\title{
PROPAGAÇÃO DA MARÉ SALINA EM UM ESTUÁRIO TROPICAL ESTRANGULADO, IPOJUCA, NE-BRASIL
}

\author{
Sayonara Raíza R. M. LINS'; Carmen MEDEIROS²*
}

\begin{abstract}
${ }^{1}$ Programa de Pós-Graduação em Oceanografia, Universidade Federal de Pernambuco, Recife, PE, Brasil. E-mail: sayonararaiza@gmail.com

${ }^{2}$ Laboratório de Oceanografia Física, Estuarina e Costeira, Departamento de Oceanografia, Universidade Federal de Pernambuco, Recife, PE, Brasil. E-mail: cmlimongi@gmail.com

*Autor correspondente
\end{abstract}

\begin{abstract}
RESUMO. O rio Ipojuca figura dentre os rios Pernambucanos que sofreram maiores alterações em sua geometria/desembocadura e descargas fluviais. Este estudo enfoca a propagação da maré salina e o regime salino neste sistema. Os trabalhos abrangeram um levantamento morfobatimétrico, obtenção de perfis CTD e medições de correntes em períodos chuvoso (jun-ago/2017) e de estiagem (dez/17) em ciclos de sizígia e quadratura. O estuário é raso $(-1,4$ a $9,1 \mathrm{~m})$ em seus trechos superior e mediano, com profundidade média de $0,5 \mathrm{~m}(0,4-9,5 \mathrm{~m})$ e presença de um canal central profundo e de bancos de areia emersos em seu trecho inferior. O estuário é do tipo 1b pelo sistema de classificação de Hansen and Rattray (1966), moderadamente estratificado e lateralmente homogêneo. O transporte salino é governado por processos difusivos, recebendo moderadas a elevadas descargas fluviais no período chuvoso e tendendo a parcialmente estratificado, com baixas entradas de água doce durante o período de estiagem. A excursão da maré salina alcança 2,0-5,7km para montante de sua desembocadura, sendo fortemente influenciada pelo regime das chuvas e secundariamente pelo ciclo das marés. A condição de barra estrangulada dificulta as trocas com a área costeira, a entrada das águas marinhas e a drenagem de águas de fundo.
\end{abstract}

Palavras-Chave: estuário, intrusão salina, regime salino, maré salina, salinidade.

\begin{abstract}
The Ipojuca figures among the Pernambuco's rivers that suffered major changes in its geometry/river mouth and river discharge. This study focuses on the propagation of salt tide and on the salt regime in this system. The work comprised a morphobymetric survey and the gathering of CTD profiles and current measurements during rainy (June-Aug/2017) and dry (Dec/2017) seasons, over spring and neap tidal cycles. The estuary is shallow $(-1.4$ to $9.1 \mathrm{~m})$ in its upper and middle stretches, with an average depth of $0.5 \mathrm{~m}(0.4-9.5 \mathrm{~m})$ and presence of a deep central channel and emerged sandbanks in its lower section. The estuary is of type 1b (Hansen and Rattray system of classification, 1966). It is moderately stratified and laterally homogeneous with saline transport being governed by diffusive processes, receiving moderate to high river discharge in the rainy season and tending to partially stratified, with low inflow of fresh water during the dry season. The excursion of the salt tide reaches 2.0$5.7 \mathrm{~km}$ upstream from its mouth, being strongly influenced by the rainfall regime and secondarily by the tidal cycle. The choked inlet reduces the exchange with the coastal area, the entrance of marine water and the drainage of bottom waters.
\end{abstract}

Keywords: estuary, salt intrusion, salinity distribution, salt tide, salinity. 


\section{INTRODUÇÃO}

Os estuários são corpos d'água costeiros semifechados conectados permanentemente ou periodicamente ao mar, com salinidade diferente daquela do oceano aberto adjacente devido à entrada de água doce, e que possuem biota característica (Whitfield and Elliott, 2011). São áreas de encontro entre águas fluviais e oceânicas, sendo amplamente utilizadas como berçários para espécies de ambos os ambientes, inclusive as economicamente importantes. Como tal, esses ambientes podem apresentar ampla variabilidade na salinidade em curtas distâncias.

Os estuários estão sujeitos à ação dos aportes fluviais, dos ventos e da oscilação das marés e apresentam padrões de circulação e de mistura diversos, em função desses forçantes como também de sua morfologia e batimetria e do uso e ocupação de sua bacia de drenagem. Os mecanismos físicos que controlam a hidrodinâmica dos ambientes estuarinos variam horizontalmente e em profundidade, influenciando diretamente o transporte e distribuição de materiais como sais, nutrientes, sedimentos, poluentes, etc. (Dyer, 1995).

Ao longo do tempo, os ambientes estuarinos contribuíram para o desenvolvimento dos centros urbanos e industriais sofrendo, em consequência, desmatamento e ocupação de suas margens para o desenvolvimento de atividades agrícolas e de aquicultura, bem como para implantação de áreas residenciais e de instalações hoteleiras, de lazer, etc. (Barbier et al., 2011).

O litoral pernambucano se estende por $187 \mathrm{~km}$ desde o município de Goiana, ao Norte, até o município de São José da Coroa Grande, ao Sul. Dentre os rios que deságuam no litoral pernambucano, o rio Ipojuca figura dentre os rios que sofreram maiores alterações em sua geometria e desembocadura (construção do Porto de Suape) bem como alterações das descargas fluviais pelas várias barragens e captação a fio d'água ao longo do mesmo.

A maioria dos trabalhos desenvolvidos na área do rio Ipojuca foram conduzidos na década de 80, 90 durante ou nos anos seguintes à implantação do Complexo Industrial Portuário de Suape e enfocaram principalmente aspectos hidrológicos, da qualidade da água e dos sedimentos (CPRH, 1995; Muniz et al., 2015; Neumann-Leitão et al., 1999; Sobral et al., 2016) e comunidades planctônicas (Barros-França and Batista, 1991; Eskinazi-Leça and Koening, 1985-86; Koening and Eskinazi-Leça, 1991; Koening et al., 2003; Koening et al., 1996; Neumann et al., 1992; Paranaguá, 1985-86), nectônicas (Vasconcelos Filho et al., 1990), bentônicas (Braga et al., 1989a), manguezal (Braga et al., 1989b) e aspectos geológicos e da bacia hidrográfica (CONDEPE/FIDEM, 2005; Monteiro et al., 2014; Neumann, 1991; Neumann et al., 1998). Estudos específicos relativos à intrusão e estrutura salina ao longo do Ipojuca são ainda escassos, com registro para os trabalhos de Araújo (1999) que efetuou uma 
caracterização hidrodinâmica para o trecho do rio Ipojuca a montante da confluência com o rio Merepe, não incluindo o baixo estuário e para o trabalho de Lins (2002) que abordou a estrutura termohalina e aspectos hidrodinâmicos no baixo estuário do rio Ipojuca. Sedimentação, aterros e dragagens ocorridas na área posteriormente a esses estudos, muito provavelmente modificaram hidrodinâmica e hidrologia no sistema. O presente estudo enfoca assim aspectos atuais da intrusão da maré salina e do regime salino ao longo de todo trecho estuarino do rio Ipojuca em função da sazonalidade do regime das chuvas.

\section{MATERIAIS E MÉTODOS}

\section{ÁREA DE ESTUDO}

O rio Ipojuca nasce nas encostas da serra Pau D'Arco, município de Arcoverde, a uma altitude de cerca de 900m (CONDEPE/FIDEM, 2005). Apresenta curso alongado de cerca de 250 km, sem afluentes importantes, desaguando no Oceano Atlântico, no limite sul do território do Complexo Industrial Portuário de Suape (CIPS). Sua bacia de drenagem (25L, $283321 \mathrm{~m} \mathrm{E-}$ $714561 \mathrm{~m} \mathrm{E} ; 9097055 \mathrm{~m} \mathrm{~N}-9040835 \mathrm{~m} \mathrm{~N}$ ) ocupa uma área de 3435 km² distribuída por 25 municípios da região Centro-Leste do Estado de Pernambuco.

O clima ao longo da bacia hidrográfica do rio Ipojuca varia de tropical quente e seco, do tipo Aw, segundo o sistema de classificação climática Köppen (Köppen, 1884), com um período chuvoso de fevereiro a junho (chuvas de verão/outono) em sua porção mais oeste (trechos superior e parte do médio) a quente e úmido (Zona da Mata) em seu trecho inferior no qual se insere a região estuarina do rio Ipojuca. Neste trecho o clima é tropical quente-úmido, do tipo

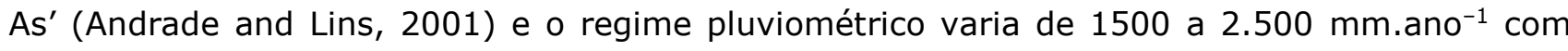
duas estações bem definidas: uma chuvosa, de março a agosto, com precipitação média mensal de $250 \mathrm{~mm}$ e outra seca de setembro a fevereiro, com precipitação média mensal de $70 \mathrm{~mm}$.

\section{AQUISIÇÃO E TRATAMENTO DOS DADOS}

Os levantamentos in situ foram conduzidos de forma a abranger os períodos chuvoso e de estiagem e a representarem os estágios de preamar, vazante, baixa-mar e enchente em ciclos de marés de sizígia e de quadratura em cada um desses períodos.

Para o desenvolvimento do trabalho, foram estabelecidas 6 estações fixas (Estações S1 a S6) ao longo do rio Ipojuca, e 17 estações intermediárias (Estações $R_{i}$ ), empregadas para refinamento dos dados e identificação do limite da intrusão salina (Fig. 1).

As estações S1 a S6 seguiram a calha natural do rio, enquanto que a estação S4 está localizada em um estreito canal artificial dragado. 
Visando uma caracterização climática e meteorológica da área, foram obtidos e compilados séries históricas e dados disponíveis para o período do estudo, da precipitação pluviométrica, temperatura do ar e da intensidade e direção dos ventos para a estação meteorológica do Porto de Suape (25 L, 282924 m E; 9071919 m N).

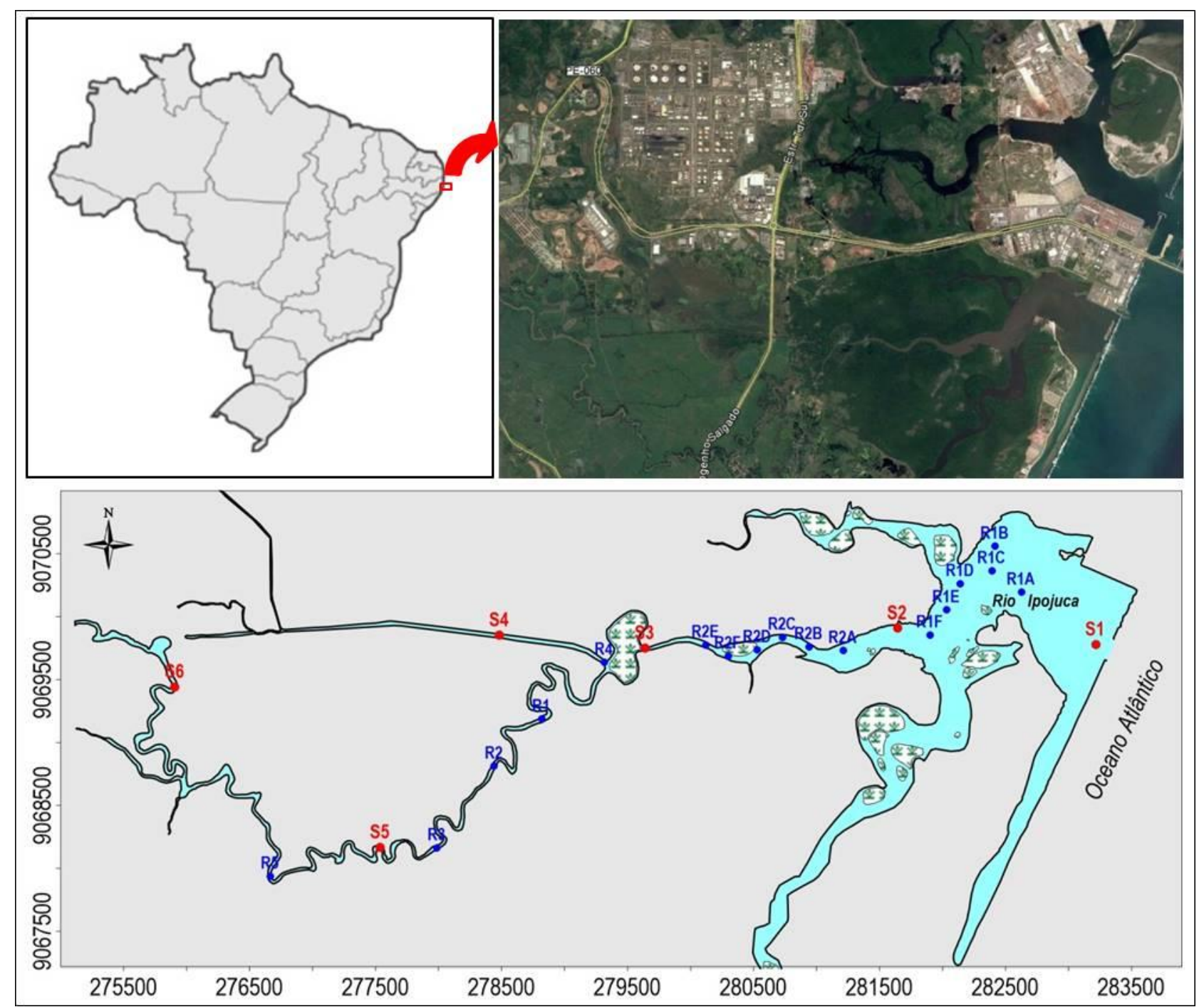

Figura 1. Área de estudo com as estações fixas e de refinamento. Os pontos vermelhos representam as estações fixas, enquanto as azuis indicam os locais escolhidos para o refinamento dos dados.

Um levantamento morfobatimétrico da área de estudo foi inicialmente realizado empregando-se uma sonda GARMIN 525s operando com transdutor de dupla frequência $50 \mathrm{kHz}$ $\left(19^{\circ}\right)$ e $200 \mathrm{kHz}\left(6^{\circ}\right)$ e uma malha amostral com um espaçamento de $10-20 \mathrm{~m}$ entre linhas de sondagem. Os levantamentos batimétricos foram realizados em outubro/16 e abril/17, resultando em um total de 23.789 pontos de sondagem referenciados ao Datum WGS 84 , e 
projetados no Sistema de Coordenadas UTM zona 25 L. Uma carta batimétrica foi elaborada com o Software Surfer15 da Golden Software, utilizando-se o método Kriging de interpolação.

Na caracterização da distribuição espaço-temporal da salinidade ao longo do estuário do rio Ipojuca, perfis CTD foram obtidos em cada uma das 6 estações amostrais, desde a superfície até o fundo, e de modo a caracterizar os estágios de baixa-mar, enchente, preamar e vazante em ciclos de marés de sizígia e quadratura durante os períodos chuvoso (jun-ago/17) e de estiagem (dez/17). Para as amostragens empregou-se um perfilador CTD Sea-bird Electronics SBE19Plus operando a uma taxa de amostragem de $4 \mathrm{~Hz}$ e dotado de sensores de Condutividade (resolução $=0.00005 \mathrm{~S} . \mathrm{m}^{-1}$ ), Temperatura (resolução $=0.0001^{\circ} \mathrm{C}$ ) e Pressão (resolução $=0.010$ $\mathrm{m})$, todos alimentados por uma bomba centrífuga SBE 5T.

Visando identificar com mais acuidade os limites de propagação da maré salina, perfis adicionais CTD foram obtidos para cada estágio de maré e espaçados a 100-800m ao longo do trecho compreendido entre a última das 6 estações amostrais em que a influência salina foi identificada e a estação imediatamente a montante desta.

Em laboratório todos dados foram transferidos para PC, sendo em seguida filtrados, reduzidos, editados (eliminação de dados fora d'água, dados faltosos, etc.). O cálculo das propriedades físicas foi realizado utilizando-se os softwares dos próprios equipamentos seguindo especificações TEOS-10 (IOC et al., 2010). Malhas uniformes das distribuições horizontais dos valores de salinidade foram obtidas interpolando-se esses dados, pelo método Kriging, com uso do Software Surfer15 da Golden Software, levando em consideração a variação espacial dos dados.

Uma classificação dos estuários com base em sua hidrologia e hidrodinâmica é desejável, uma vez que permitiria compará-los em função das principais forçantes e/ou processos que atuam nos mesmos. Dentre os vários sistemas propostos para tal, o por Hansen and Rattray (1966) é o mais amplamente empregado e foi aqui utilizado. O mesmo consiste em um diagrama conectando dois parâmetros adimensionais que representam os graus de circulação (eixo OX) e de estratificação (eixo OY) nos estuários integrados ao longo do ciclo das marés. O parâmetro de circulação é $\mathrm{U}_{\mathrm{s}} / \mathrm{U}_{\mathrm{f}}$, onde $\mathrm{U}_{\mathrm{s}}$ é a corrente média longitudinal à superfície e $\mathrm{U}_{\mathrm{f}}$ é a corrente média longitudinal através da secção estuarina. O parâmetro da estratificação é $\partial \mathrm{S} / \mathrm{S}_{0}$, onde $\partial \mathrm{S}$ é a diferença entre a salinidade à superfície e de fundo e $\mathrm{S}_{0}$ é a salinidade média da coluna d'água. Para tanto, paralelamente a obtenção dos perfis CTD, medições da intensidade e direção das correntes foram realizadas em dois níveis de profundidade (superfície e fundo) com uso de correntômetro Sensordata SD30. 


\section{RESULTADOS \\ CLIMATOLOGIA E METEOROLOGIA}

A série histórica da estação meteorológica do Porto de Suape (25L, 283077 m E; 9072042 m N) teve início em maio/2013 (Fig. 2).

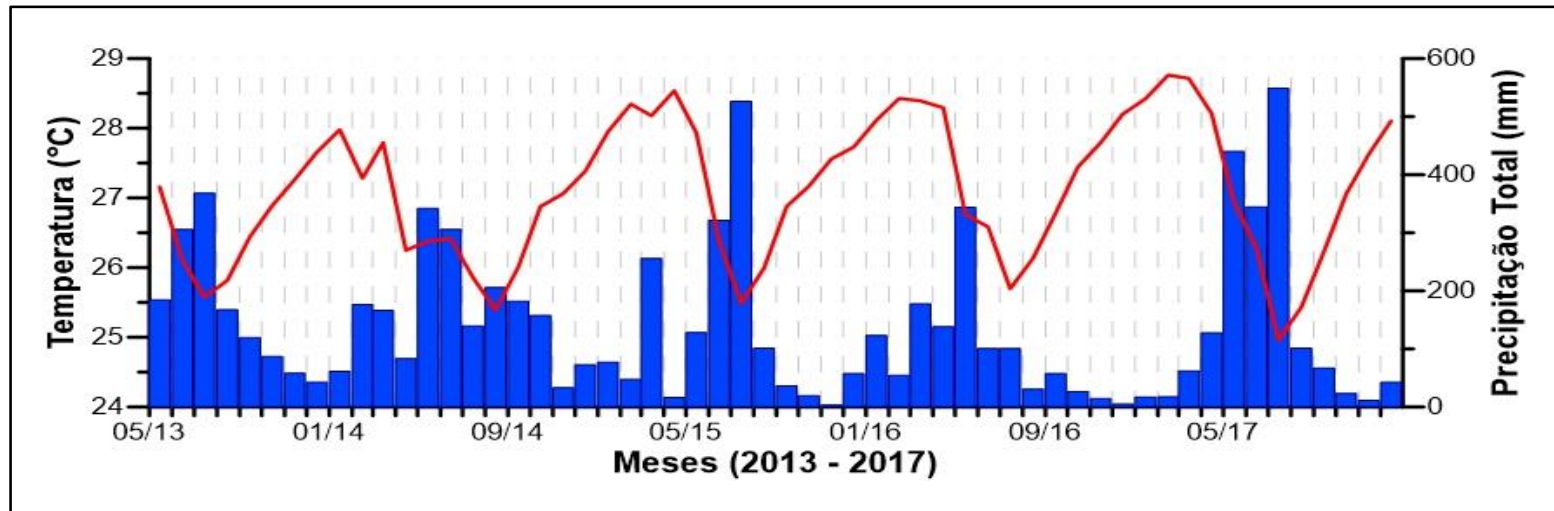

Figura 2. Precipitação pluviométrica (barras azuis) e Temperatura (linha vermelha) média mensal para a estação meteorológica do Porto de Suape, Ipojuca para o período de 2013 a 2017.

Os máximos de temperatura média e precipitação mensal ocorreram ambos no ano de 2017, ultrapassando os valores dos últimos quatro anos e tendo alcançado $28,76^{\circ} \mathrm{C}$ em fevereiro, com um total de precipitação de 548,40 mm no mês de julho. Ainda em 2017, durante o ano da realização do estudo, foi registrado, em julho de 2017, o menor valor mensal de temperatura $\left(24,96^{\circ} \mathrm{C}\right)$. A menor média mensal de precipitação foi observada em novembro de 2015.

O ano de 2017 apresentou uma sazonalidade bem marcada, sendo observados períodos de baixa precipitação (16,6 e 17,2 mm em jan-fev) e altas temperaturas, maior dos últimos quatro anos, durante o início do ano (jan-mar), seguido por um período de grande volume de chuvas e baixas temperaturas no período chuvoso, chegando a 548,4 mm durante o mês de julho, e logo após apresentando novamente baixíssimos valores de precipitação (11 mm em novembro) e altas temperaturas durante o período de estiagem em dezembro.

Os períodos de coleta foram representativos dessa sazonalidade, o volume de chuvas no Porto de Suape - e em grande parte da extensão da bacia do Ipojuca - foi elevado e com baixas temperaturas durante as coletas do período chuvoso, como indicado anteriormente, e apresentando baixíssimos valores de precipitação $(42,2 \mathrm{~mm})$ e temperaturas elevadas $\left(28,1^{\circ} \mathrm{C}\right)$ durante as coletas de estiagem.

Registros da estação meteorológica do Porto de Suape indicaram para o ano de 2017, a predominância de ventos na direção sudeste (SE) $131^{\circ}$ e velocidade média de $3,05 \mathrm{~m} \mathrm{~s}^{-1}$. 
Durante o período chuvoso, os ventos predominantes foram de SE $\left(148^{\circ}\right)$, com velocidade de $3,4 \mathrm{~m} \mathrm{~s}^{-1}$. Durante o período de estiagem, predominaram ventos de $\mathrm{E}\left(91^{\circ}\right) \mathrm{com}$ velocidade média de $2,7 \mathrm{~m} \mathrm{~s}^{-1}$.

\section{MORFOBATIMETRIA}

O rio Ipojuca se conecta com o Oceano Atlântico através de um corte de cerca de $150 \mathrm{~m}$ e rebaixamento parcial da linha de recife, aberto após execução do aterro para construção do Porto de Suape que isolou o rio de sua desembocadura natural. O baixo estuário do Ipojuca apresenta uma forma afunilada, com largura de 985 m próxima à estação S1, de $420 \mathrm{~m}$ na região de confluência com o rio Merepe e de $190 \mathrm{~m}$ à estação S2 (Fig. 3). Esse trecho forma uma espécie de laguna, com profundidade média de 0,5 m e variáveis entre $-1,4$ e 9,1 m, apresentando um canal central mais profundo e bancos de areia emersos. À estação S2 um canal mais profundo se apresenta próximo à margem direita, alternando de posição à medida que se apresentam os meandros.

Após a laguna, a calha do Ipojuca torna-se cada vez mais estreita, com largura de 33,4m à estação S3, seguindo um curso sinuoso com vários meandros. Em seu trecho mediano, prevalecem profundidades mais rasas $(-1,2$ a $3,3 \mathrm{~m})$, enquanto que no superior prevalecem profundidades de $-0,3$ a $6,3 \mathrm{~m}$ (Fig. 3).

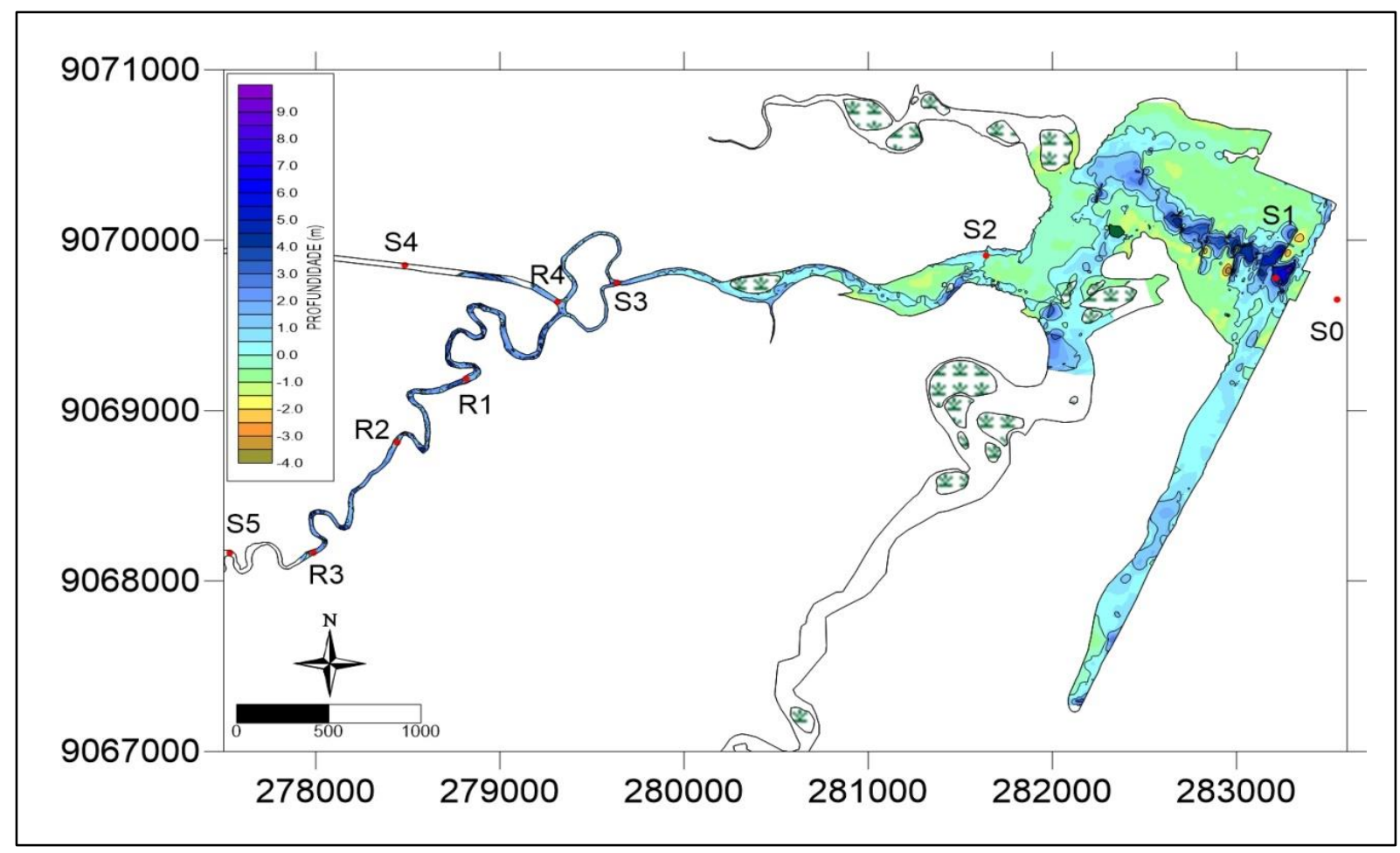

Figura 3. Carta morfobatimetrica do estuário do rio Ipojuca. Cotas (m) referidas ao RN da DHN para o Porto de Suape. 


\section{REGIME SALINO}

A distribuição espacial da salinidade durante os estágios de baixa-mar, enchente, preamar e vazante ao longo da área de estudo são apresentadas nas figuras 4 e 5 e 6 e 7, respectivamente para os ciclos de quadratura e sizígia durante os períodos chuvoso e de estiagem.

Durante o período chuvoso, o trecho compreendido entre as estações S1 e S2 (quadratura) e entre as estações S1 e S3 (sizígia) apresenta um gradiente salino vertical desde a superfície até o fundo, caracterizado pela inclinação das isohalinas (Figs 4 e 5). Próximo à superfície a salinidade varia entre 2 e 32 à estação $S 1$ ao longo do ciclo das marés, enquanto que próximo ao fundo a variabilidade é menor (24 a 35). Durante o ciclo de sizígia no período chuvoso, à estação S1, a coluna d'água apresentou salinidade próxima a nula durante a baixamar a salinidade típica marinha durante a preamar (Fig. 5).

À estação S2, os valores de salinidade à superfície variaram de 0,2 e 4,2 durante a quadratura e entre 0,2 e 5,3 durante a sizígia. O trecho ao longo do rio Ipojuca compreendendo as estações S4 a S6 apresentou uma coluna d'água bem misturada, com salinidades sempre inferiores 0,5 . À estação $S 3$, a salinidade foi igualmente reduzida durante a quadratura, com uma pequena assinatura de salinidade apenas à superfície durante a preamar, mas com valores varáveis entre 0,2 e 12,1 à superfície e entre 0,2 e 32,2 próximos ao fundo durante a sizígia.

Durante o período de estiagem (Figs. 6 e 7) a salinidade foi em geral mais elevada e o gradiente salino vertical presente no trecho compreendido pelas estações S1 a S3 e S4 mais acentuado (isohalinas mais horizontalizadas) relativo ao encontrado no período chuvoso. À superfície, a salinidade variou entre 14 e 36 e entre 12 e 32 respectivamente nas estações S1 e S2 durante a quadratura e entre 18 e 36 e entre 4 e 34 durante a sizígia. Próximo ao fundo a salinidade foi pouco variável à estação S1 (32 a 36) tanto na sizígia quanto na quadratura. Na estação S2 a salinidade ao longo da coluna d'água foi mais elevada nos estágios de vazante e preamar (28 a 32) e mais reduzida nos estágios de baixa-mar e enchente, tanto na sizígia quanto na quadratura. Na estação S3, em regime de sizígia e quadratura, a salinidade apresentou-se reduzida para os primeiros $2 \mathrm{~m}$ de coluna d'água $(<5)$ mas com valores até 28 próximos ao fundo. Na estação S4, no canal artificial, tanto na sizígia quanto na quadratura, a salinidade foi reduzida ao longo de quase toda a coluna d'água $(<2)$, com valores de 4 a 12 para o último metro. À estação S5 e S6 a coluna d'água mostrou-se bem misturada, com salinidade sempre inferior a 0,2 na sizígia e quadratura. 


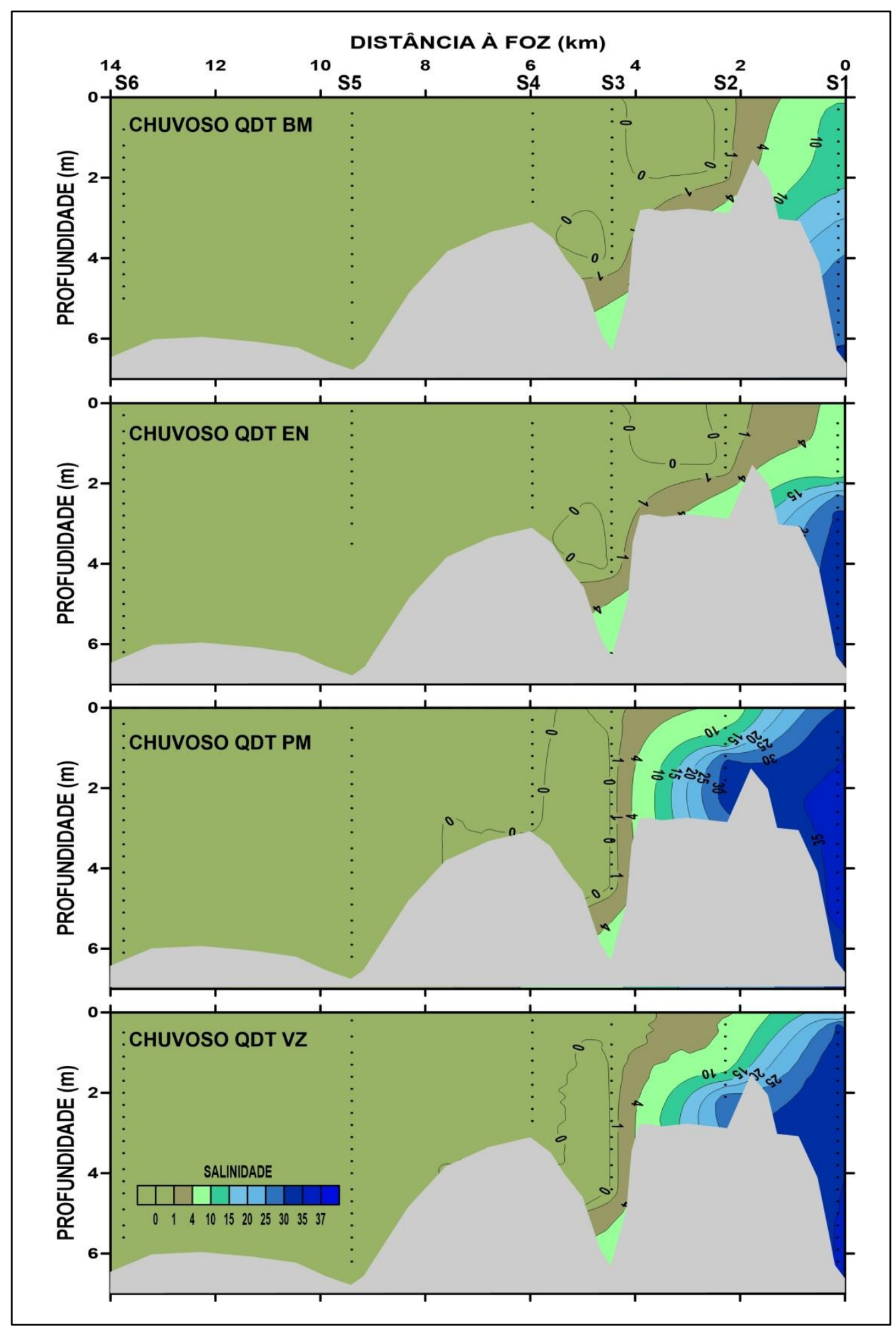

Figura 4. Distribuição vertical da salinidade ao longo da área de estudo, em estágios de baixa-mar (BM), enchente (EN), preamar (PM) e vazante (VZ) durante uma quadratura (QDT) no período chuvoso. 


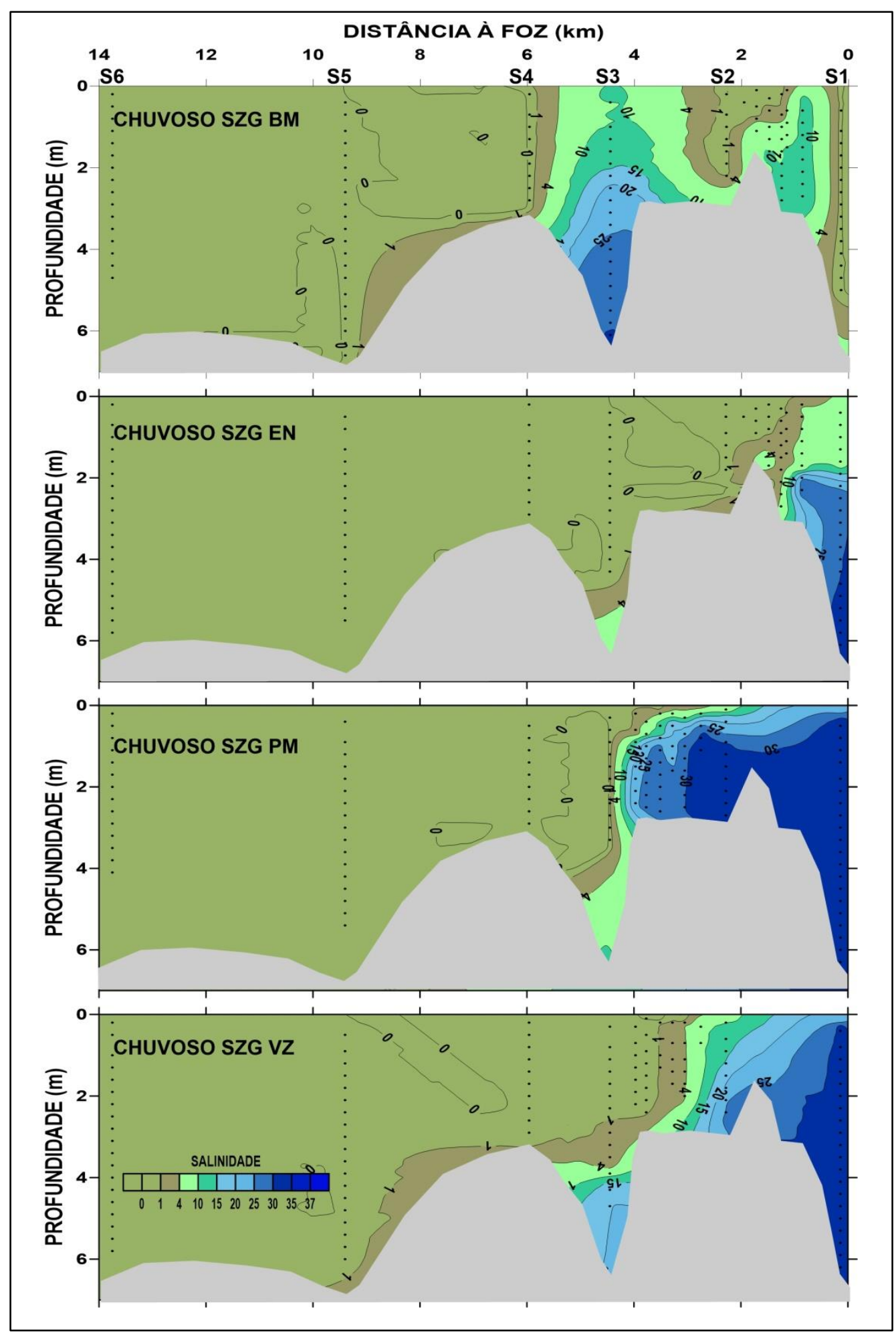

Figura 5. Distribuição vertical da salinidade ao longo as área de estudo em estágios de baixa-mar (BM), enchente (EN), preamar (PM) e vazante (VZ) durante uma sizígia (SZG) no período chuvoso. 


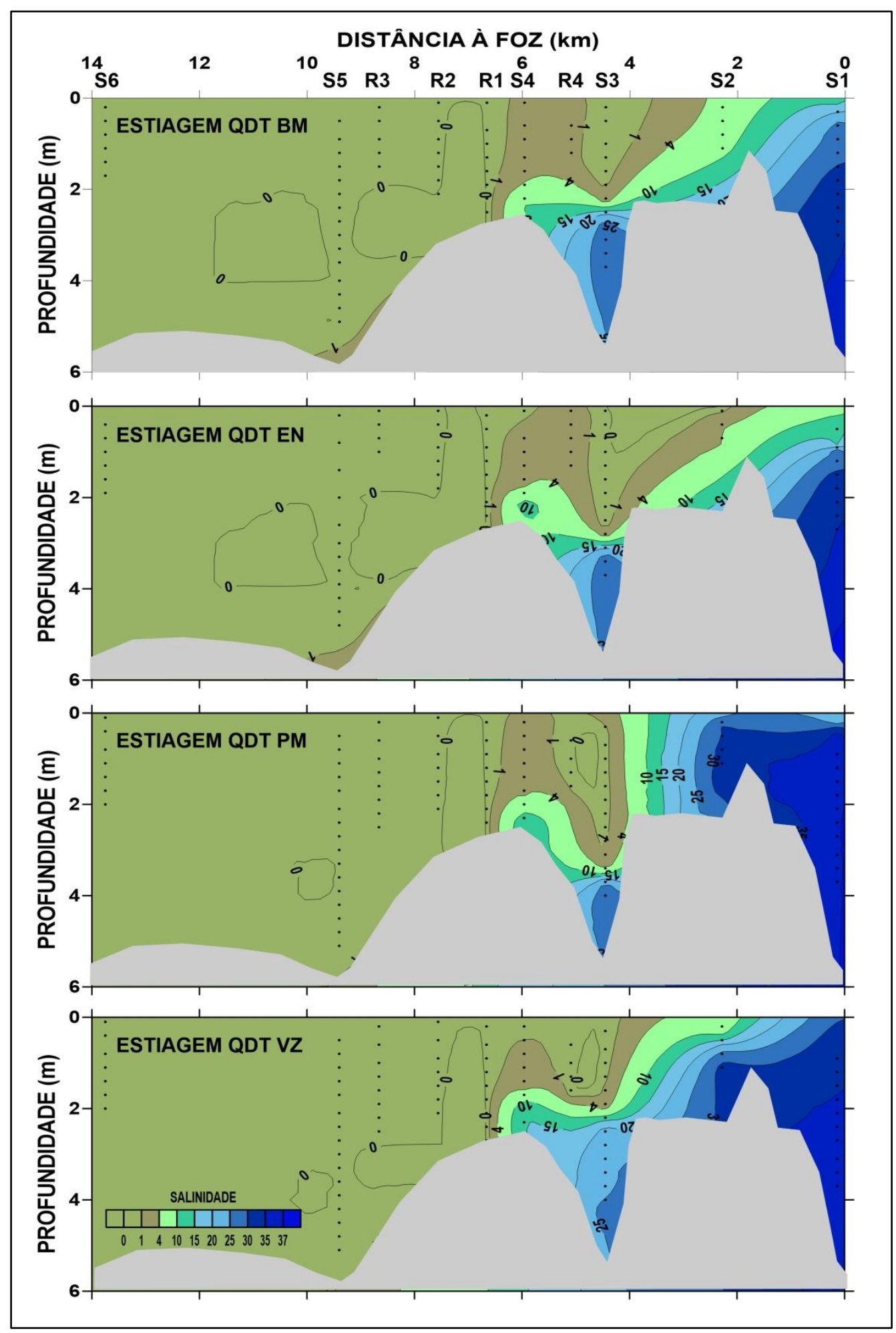

Figura 6. Distribuição vertical da salinidade ao longo da área de estudo em estágios de baixa-mar (BM), enchente (EN), preamar (PM) e vazante (VZ) durante uma quadratura (QDT) no período de estiagem. 


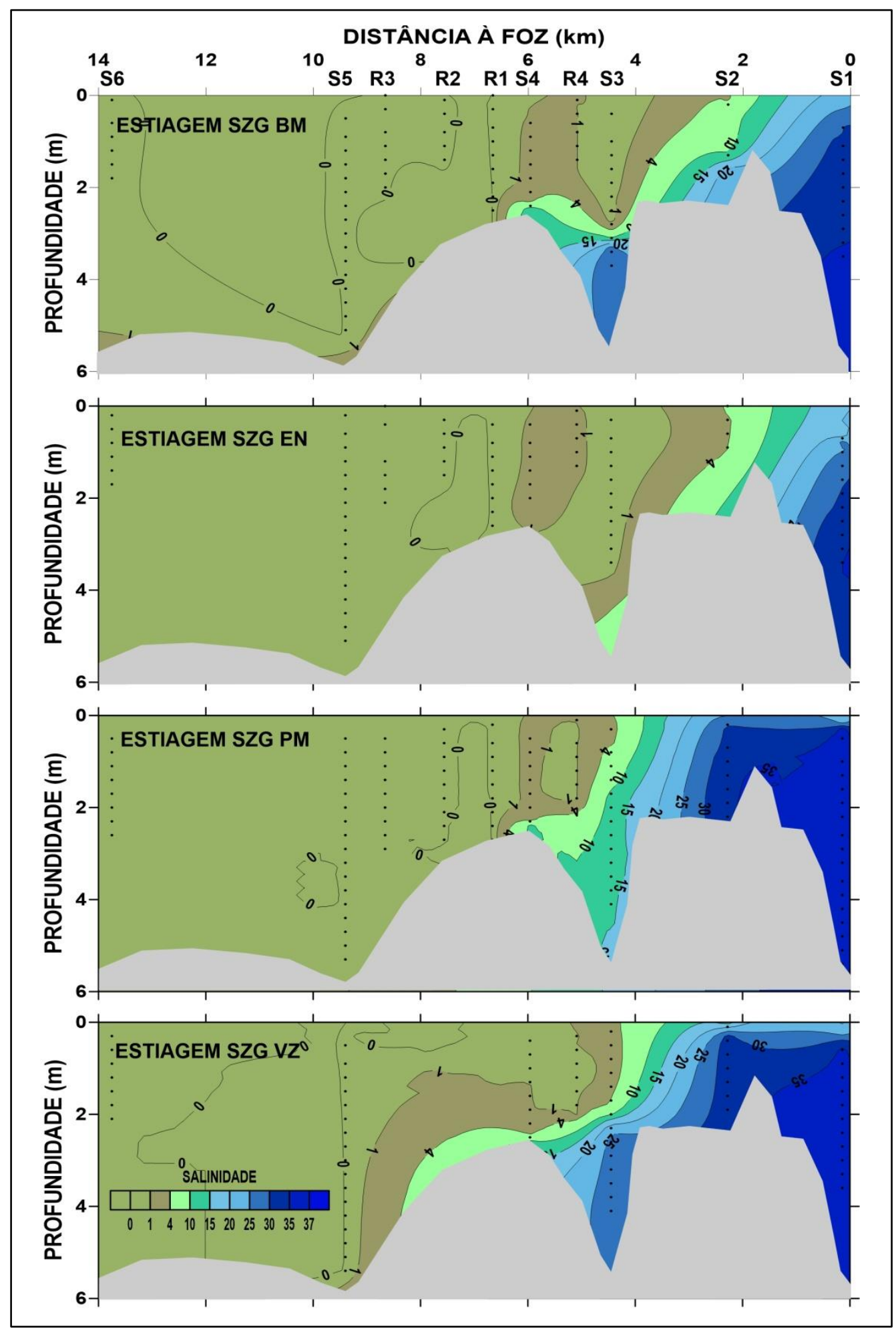

Figura 7. Distribuição vertical da salinidade ao longo da área de estudo em estágios de baixa-mar (BM), enchente (EN), preamar (PM) e vazante (VZ) durante uma sizígia (SZG) no período de estiagem. 


\section{LIMITE DA INTRUSÃO SALINA}

A Fig. 8 representa os limites máximos de penetração da maré salina na área de estudo para os períodos chuvoso e de estiagem em ciclos de maré de sizígia e de quadratura. Os limites para um estágio específico de maré são indicados pelas setas enquanto a área hachurada representa a região de excussão da maré salina durante o ciclo de maré considerado.

Durante o período chuvoso, a penetração da maré salina ao longo do rio Ipojuca alcançou entre 2,0 e 5,4 km para montante de sua desembocadura na sizígia e entre 2,3 e 4,4 km na quadratura. Já no período de estiagem a excursão salina alcançou áreas mais interiores do rio, se estendendo por 5,3 a 5,7 km para montante da desembocadura na sizígia e por 5,6 a 5,7 km na quadratura.

Além da menor penetração e maior variabilidade da excursão da maré salina entre os estágios de maré durante o período chuvoso, relativa àquela no período de estiagem, verifica-se também diferenças entre os estágios de maré em que a excursão das águas salinas atinge seu limite máximo em cada período sazonal.

No período chuvoso, a maior incursão das águas salinas ocorre durante a vazante/baixamar na sizígia e durante a preamar/vazante na quadratura. No período de estiagem as maiores excursões das aguas salinas se deram durante os estágios de enchente/baixa-mar na quadratura e durante os estágios de preamar/vazante durante a sizígia.

\section{CLASSIFICAÇÃO ESTUARINA}

Neste trabalho foi utilizado o sistema proposto por Hansen and Rattray (1966) para a classificação do estuário do rio Ipojuca. Os valores dos parâmetros de circulação e estratificação às estações S1, S2 e S3, foram computados em função dos períodos sazonais (chuvoso e estiagem) e dos regimes de maré (sizígia ou quadratura) e plotados no referido diagrama (Fig. 9).

De forma geral, o estuário do rio Ipojuca foi classificado como do tipo 1b para a região do baixo estuário (estações S1 e S2) tanto no período chuvoso quanto no de estiagem. A posição no diagrama reflete um baixo estuário (S1-S2) lateralmente homogêneo, no qual o transporte salino é dominado por processos difusivos $(v>0,9)$ e que apresenta estratificação moderada recebendo entradas razoáveis de água doce, sobretudo no período chuvoso, tendendo a sistemas parcialmente estratificados com baixas entradas de água doce durante o período de estiagem.

Já o trecho do médio estuário (S3) sob maior influência da descarga fluvial, foi classificado como tipo 1 b durante o período chuvoso e como do tipo 4 durante o período de estiagem. 
Ambientes de classificação tipo 4, ou cunha salina, tem como característica a presença de forte estratificação e transporte gerado por processos advectivos fluviais e gravitacionais $(v<0,1)$.

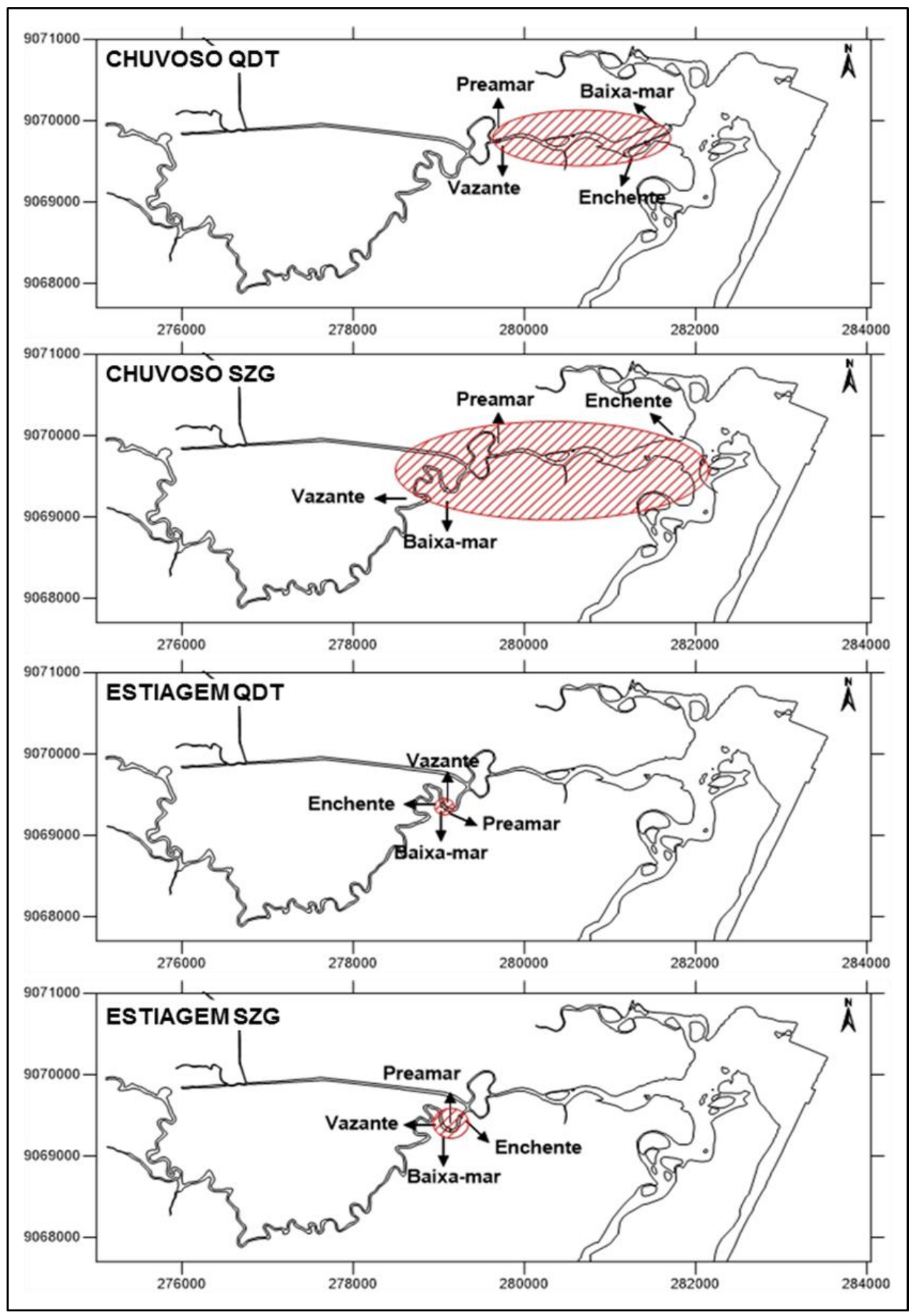

Figura 8. Limites da maré salina ao longo do estuário do rio Ipojuca durante a sizígia do período chuvoso. Cada estágio da maré apresentou um limite distinto, sendo a área hachurada correspondente à área de variação do limite salino. 


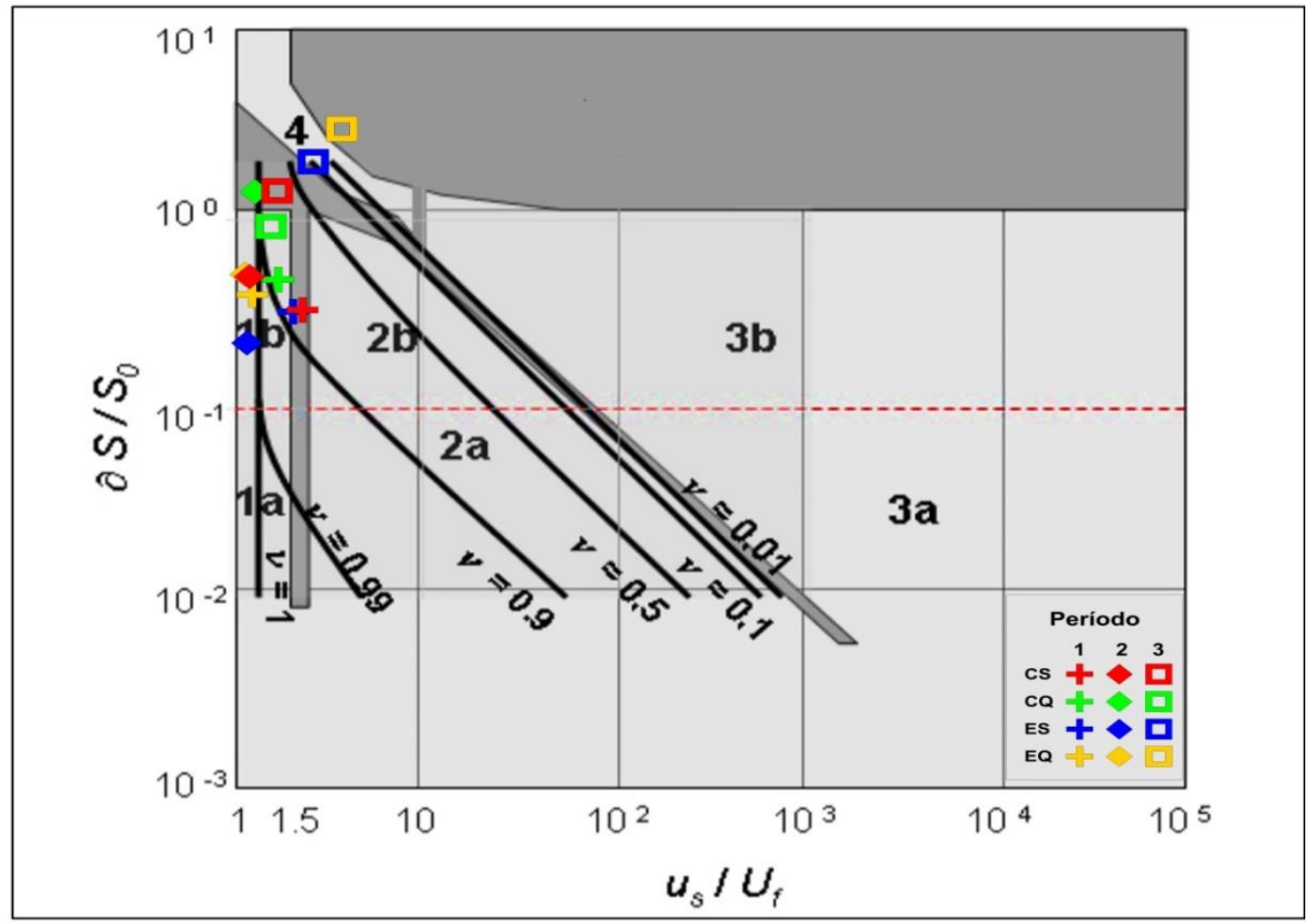

Figura 9. Diagrama de classificação estuarina de Hansen and Rattray (1966) para o estuário do rio Ipojuca à estação $\mathrm{S} 1$, S2 e S3 nos períodos chuvoso (C) e de estiagem (E), durante ciclos de sizígia (S) e de quadratura (Q).

\section{DISCUSSÃO}

Na região tropical, há pouca variação de temperatura, fazendo com que a diferenciação ocorra pela intensidade de insolação e comportamento dos ventos. Segundo Manso et al. (2006), os ventos alísios e as brisas marinhas exercem influência nos ambientes costeiros sendo que direção e velocidade dos ventos no litoral pernambucano é, em $90 \%$ dos casos, observado no setor E-SE com médias de velocidade entre 3 e $5 \mathrm{~m} \mathrm{~s}^{-1}$, corroborando com a encontrada na estação meteorológica de Suape (média $135,4^{\circ} ; 3,05 \mathrm{~m} \mathrm{~s}^{-1}$ ).

A precipitação acumulada de 2017 encontra-se na média pernambucana, totalizando 1800,2 mm, contudo sua distribuição foi distinta dos demais anos no local de estudo. Observando os dados da série meteorológica do porto de Suape, os meses de maio a julho representaram menos do que 50\% do total anual nos anos anteriores, enquanto que em 2017 esses mesmos meses corresponderam a 74\%. Durante as coletas, os meses amostrados foram bem característicos de cada período, permitindo analisar de forma satisfatória a dinâmica estuarina durante o período chuvoso e de estiagem. 
Segundo Savenije (2012) e Shaha et al. (2011), a hidrodinâmica estuarina depende principalmente da descarga fluvial e da maré. Durante o período chuvoso e nos estágios de vazante e baixa-mar, o estuário tenderia a apresentar salinidades mais reduzidas, em função da maior influência fluvial e menor influência das águas marinhas adentrando o mesmo. Por outro lado, as maiores salinidades seriam esperadas durante períodos de estiagem e nos estágios de preamar e enchente.

Durante o período chuvoso, a presença de águas salinas ficou restrita ao baixo estuário, entre as estações S1 e S2, alcançando a estação S3 apenas em alguns estágios do ciclo das marés. Já no período de estiagem, a salinidade foi em geral mais elevada, com presença de águas salinas no baixo e médio estuário.

No estuário do rio Ipojuca relativo aos estágios de maré para as previsões da Diretoria de Hidrografia e Navegação, DHN para o Porto de Suape, durante o período chuvoso as maiores excursões das águas salinidades foram registradas nos estágios de preamar e vazante da quadratura (salinidades de 31,8 e 28,4 na camada de fundo à estação S3, respectivamente) e durante os estágios de vazante e baixa-mar na sizígia (salinidade de 30,5 e 19,9 na camada de fundo à estação S3, respectivamente), indicando uma permanência mais longa das águas salinas no interior do sistema, havendo a redução de salinidade apenas durante a enchente. As diferenças de fase observadas parecem estar relacionadas à condição de barra estrangulada, que dificulta as trocas com a área costeira e entrada das águas marinhas e a drenagem de águas mais próximas ao fundo e a alta descarga fluvial no período chuvoso.

Apenas no período de estiagem a influencia as águas marinhas alcançou a estação S3 durante o estágio de vazante tendo alcançado apenas $700 \mathrm{~m}$ para montante da estação S1 durante a quadratura do período chuvoso.

No período de estiagem essa diferença é menos pronunciada trecho entre as estações S1 e S2, estando mais evidente à estação S3. A influência das águas salinas ultrapassa a estação $\mathrm{S} 3$ em todos os estágios da maré tanto em regime de quadratura quanto de sizígia. Contudo, durante a quadratura quando a intrusão salina é menor as salinidades apresentaram-se mais reduzidas.

Durante o período de estiagem a penetração das águas marinhas alcançou sempre a região da estação S3, independentemente do estágio do ciclo das marés, ao passo que durante o período chuvoso a extensão dessa excursão esteve fortemente condicionada ao ciclo das marés, alcançando maiores extensões durante os estágios de baixa-mar e enchente na quadratura e durante os estágios de vazante e baixa-mar na sizígia.

A variação de salinidade é mais intensa longitudinalmente em estuários rasos, como é o caso do estuário do rio Ipojuca. A distribuição da salinidade e suas flutuações influenciam a distribuição da biota nos estuários, sendo indispensável em qualquer pesquisa de gestão 
estuarina o entendimento de seu comportamento e distribuição para subsidiar as tomadas de decisões (Barletta and Blaber, 2007; Barletta et al., 2003; Junior et al., 2017; Paiva et al., 2008).

O limite de penetração da maré salina em um sistema estuarino varia ao longo do ciclo de maré e em função de seu regime das mesmas. Em regime de maré de sizígia, a variabilidade na distância de excursão da maré salina é geralmente mais acentuada devido a sua maior amplitude de oscilação de nível, resultando tanto em uma excursão máxima rio a cima quanto em uma excussão mínima mais próximo à desembocadura do estuário. Já em regime de quadratura, quando a diferença de nível entre preamar e baixa-mar são menores, os limites de excussão da maré salina ao longo do estuário mostram-se menos variável.

Valores de salinidade medidos pela Agência Estadual de Meio Ambiente ( $\mathrm{CPRH}$ ) no âmbito do Programa de Qualidade das Águas Superficiais da Bacia Hidrográfica do rio Ipojuca no período de 2011 a 2017 para a estação IP97, localizada ao fundo da baía do Ipojuca, próxima a estação de refinamento R1B e R1C, corroboram os resultados obtidos, com salinidades média para o período de 31 , variando entre 19 e 37.

Segundo o critério e classificação estuarina de Hansen and Rattray (1966), um estuário é classificado como tipo 1 quando apresenta dominância de transporte salino a partir de processos de difusão e homogeneidade lateral, podendo se apresentar pouco (Tipo 1a) ou fortemente estratificado (Tipo 1b). O estuário do Ipojuca foi classificado como tipo $1 \mathrm{~b}$ para a região do baixo estuário (estações S1 e S2) durante todos os períodos amostrados. Apresentando maior e menor grau de estratificação durante a quadratura de verão e a sizígia chuvosa, respectivamente.

Análises anteriores para o rio Ipojuca realizadas por Lins (2002) classificaram o baixo estuário do rio Ipojuca como do tipo 1a e como tipo $1 \mathrm{~b}$ apenas durante a quadratura do período chuvoso. Essa diferença em comportamento evidencia a forte dependência do sistema ao regime de chuvas, com o sistema apresentando estratificação mais moderada, como ocorrido em 2000 ou migrando para o tipo 1b, sob regime de elevada precipitação e descarga fluvial como ocorrido em 2017. Um comportamento sazonal variando entre Tipo 1a no período chuvoso a Tipo 1b no período de estiagem foi descrito para o sistema estuarino de Itamaracá (Medeiros, e Kjerfve, 1993) e para o baixo estuário do rio Capibaribe (Noriega et al., 2013), ambos no litoral Pernambucano.

A mudança na classificação pode refletir também a mudança morfológica do sistema, uma vez que a geomorfologia do ambiente estuarino tem implicações para sua dinâmica. Atualmente o estuário possui um canal profundo central quase retilíneo e bancos arenosos, enquanto que à época dos levantamentos de Lins (2002) o canal principal apresentava-se mais raso e sinuoso 
com caminhamento próximo à margem esquerda, contornando um extenso banco central que foi posteriormente dragado, formando o canal central e mais profundo atual.

Observando os parâmetros empregados na classificação do estuário do rio Ipojuca, tem-se que o parâmetro de estratificação às estações S1 e S2 no período chuvoso apresentou mesma magnitude tanto em regime de quadratura quanto de sizígia, e maiores valores nos estágios de enchente e baixa-mar à estação S1 e nos estágios de vazante e preamar à estação S2. Já à estação S3 apresentou diferença de 1 estágio de maré entre as comparações das duas marés, sendo os maiores e menores valores da sizígia nos estágios de vazante e enchente enquanto que na quadratura esses valores são encontrados nos estágios de preamar e baixa-mar, respectivamente. O período de estiagem apresentou um padrão bem definido tanto em regime de sizígias quanto de quadratura. Em geral, à estação S1 o estuário apresentou características do tipo $1 \mathrm{~b}$ e altos valores de v. À estação $\mathrm{S} 2$ o comportamento foi mais variável, mas mantendo-se sempre como Tipo 1 e pouco estratificado apenas nos estágios de preamar e vazante durante as sizígias e no estágio de preamar durante a quadratura. O maior grau de estratificação foi observado à estação S3, com os valores plotados no diagrama caindo próximos ou no quadrante do tipo 4 (cunha salina).

\section{CONCLUSÕES}

A excursão da maré salina ao longo do rio Ipojuca variou entre 2,0 e 5,7 km para montante de sua desembocadura, sendo fortemente influenciada pelo regime das chuvas na região bem como pela condição estrangulada de sua desembocadura. Igualmente, o regime salino dentro do sistema, mostrou forte sazonalidade com baixas salinidades em eventos de intensa precipitação a salinidades elevadas, próximas àquela das águas costeiras, sob condições de estiagem prolongada. O regime salino em sistemas estuarinos condiciona a flora e fauna local e assim a delimitação da influência máxima marinha nos mesmos e o conhecimento de sua variabilidade e distribuição, constituem valioso subsídio para ações voltadas a proteção e recuperação desses sistemas.

O estuário do rio Ipojuca foi classificado como do subtipo $1 \mathrm{~b}$ segundo o sistema de classificação de Hansen and Rattray (1966), indicando que suas águas apresentam estratificação moderada a forte e que o processo dominante de penetração salina é derivado dos movimentos advectivos da maré.

\section{AGRADECIMENTOS}

Os autores agradecem o apoio do Sr. Isaac Cristiano de Freitas durante os trabalhos de mar, à APAC, Agência Pernambucana de Águas e Climas, pela cessão dos dados climatológicos e 
ao CNPq Conselho Nacional de Desenvolvimento Científico e Tecnológico pela concessão da bolsa de estudo à primeira autora.

\section{REFERÊNCIAS}

Agência Estadual De Planejamento E Pesquisas De Pernambuco (CONDEPE/FIDEM) (2005), Série Bacias Hidrográficas de Pernambuco, Vol. 1, rio Ipojuca, 64 p.

Andrade, G.O. and Lins, R.C.O. (2001), Clima do Nordeste, Revista de Geografia DCG/UFPE NAPA, Vol. 17, n. 1, pp. 3-32.

Araujo, M.C. (1999), Serviços de oceanografia física para o sistema estuarino do Ipojuca - PE, Relatório Técnico. Recife, 23 p.

Barbier, E.B., Hacker, S.D., Kennedy, C.J., Koch, E.W., Stier, A.D. and Silliman, B.R. (2011), The Value of Estuarine and Coastal Ecosystem Services, Ecological Monographs, Vol. 81, n. 2, pp. 169-193.

Barletta, M. and Blaber, S.J.M. (2007), Comparison of fish assemblage and guilds in tropical habitats of the Embley (Indo-West Pacific) and Caeté (Western Atlantic) estuaries, Bulletin of Marine Science, Vol. 80, pp. 647-680.

Barletta, M., Barletta-Bergan, A., Saint-Paul, U. and Hubold, G. (2003), Seasonal changes in density, biomass, and diversity of estuarine fishes in tidal mangrove creeks of the lower Caeté Estuary (northern Brazilian coast, east Amazon), Marine Ecology Progress Series, Vol. 256, pp. 217-228.

Barros-França, L.M and Batista, R.N. (1991), Distribuição horizontal e abundância relativa do fitoplâncton no complexo estuarino lagunar de Suape, in Anais $4^{\circ}$ Encontro Brasileiro de Plâncton, Universidade Federal de Pernambuco, Recife, pp. 97-116

Braga, R.A.P., Maestrini, P. and Lins, M.F. (1989a), Impacto da Implantação do Complexo Industrial-Portuário de Suape-PE sobre as populações de moluscos comestíveis, Anais da Sociedade Nordestina de Zoologia, Vol. 33, pp. 137-153.

Braga, R.A.P., Moura, H.F. and Duarte, M.T. (1989b), Impactos ambientais sobre a estrutura do manguezal de Suape, in Universidade Federal de Pernambuco, Departamento de Biologia Geral, Laboratório de Ecologia, Avaliação de Impactos Ambientais em Zonas Estuarinas em Pernambuco, Recife, pp. 32-42

Companhia Pernambucana de Recursos Hídricos (CPRH) (1995), Relatório das indústrias e carga potencial, remanescente e equivalente da bacia do rio Ipojuca, Recife, não paginado. 
Dyer, K.R. (1995), Sediment Transport Processes in Estuaries, in Perillo, G.M.E. (Ed.), Geomorphology and Sedimentology of Estuaries: Developments in Sedimentology, New York, Elsevier Science B.V., pp. 423-449.

Eskinazi-Leça, E. and Koening M.L. (1985-86), Distribuição das diatomáceas (Bacillariophyceae) na área de Suape (Pernambuco-Brasil), Trabalhos Oceanográficos da Universidade Federal de Pernambuco, Vol. 19, pp. 73-100.

Hansen, D.V. and Rattray, M. (1966), New dimensions in estuarine classification, Limnology and Oceanography, Vol. 11, pp. 319-326.

IOC, SCOR and IAPSO (2010), The International Thermodynamic Equation of Seawater - 2010: Calculation and use of thermodynamic properties, Intergovernmental Oceanographic Commission, Manuals and Guides 56, UNESCO, 196 p.

Junior, M.G.S., Castro, A.C.L. and Saint-Paul, U. (2017), Comparative Analysis of Distribution of Intertidal Fish Assemblages in Different Estuarine Systems on Northern Coast of Brazil, Journal of Sustainable Development, Vol. 10, n. 2, pp. 26-36.

Koening, M.L and Eskinazi-Leça, E. (1991), Aspectos quantitativos do fitoplâncton na área estuarina de Suape (Pernambuco), in Anais $4^{\circ}$ Encontro Brasileiro de Plâncton, Universidade Federal de Pernambuco, Recife, pp. 55-60.

Koening, M.L., Eskinazi-Leça, E. and Carvalho, F.A. (1996), Análise ecológica da diatomoflora do estuário do rio Ipojuca (Suape-Pernambuco-Brasil), Trabalhos Oceanográficos da Universidade Federal de Pernambuco, Vol. 24, pp. 61-77.

Koening, M.L., Eskinazi-Leça, E., Neumann-Leitão, S. and Macêdo, S.J de. (2003), Impacts of the construction of the Port of Suape on Phytoplankton in the Ipojuca River Estuary (Pernambuco-Brazil), Brazilian Archives of Biology and Technology, Vol. 46, n. 1, pp. 7381.

Köppen, W. (1884), Translated by Volken, E. and Brönnimann, S., (published 2011), "Die Wärmezonen der Erde, nach der Dauer der heissen, gemässigten und kalten Zeit und nach der Wirkung der Wärme auf die organische Welt betrachtet" [The thermal zones of the earth according to the duration of hot, moderate and cold periods and to the impact of heat on the organic world)], Meteorologische Zeitschrift, Vol. 20, n. 3, pp. 351-360.

Lins, A.M. (2002), Hidrologia e hidrodinâmica do baixo estuário do rio Ipojuca, PE, Dissertação de Mestrado, Programa de Pós-Graduação em Oceanografia, Universidade Federal de Pernambuco, 74p.

Manso, V.A.V., Coutinho, P.N., Guerra, N.C. and Soares Junior, C.F.A. (2006), Pernambuco, in Muehe, D. (Org.), Erosão e Progradação do Litoral Brasileiro. Ministério do Meio Ambiente, Brasília, pp.179-196. 
Medeiros, C. and Kjerfve, B. (1993), Hydrology of a tropical estuarine system: Itamaracá Brazil, Estuarine, Coastal and Shelf Science, Vol. 36, pp. 495-515.

Monteiro, K. de A., Tavares, B. de A.C. and Correa, A.C. de B. (2014), Aplicação do índice de Hack no rio Ipojuca para identificação de setores anômalos de drenagem e rupturas de relevo, Geociências, Vol. 33, n. 4, pp. 616-628.

Muniz, K., Neto, B.B., Macêdo, S.J. de and Pinheiro Filho, W.C. (2005), Hydrological Impact of the Port Complex of Suape on the Ipojuca River (Pernambuco-Brazil), Journal of Coastal Research, Vol. 21, n. 5, pp. 909-914.

Neumann, S., Paranaguá, M.N. and Valentin, J.L. (1992), The planktonic rotifers of the estuarine lagunar complex of Suape (Pernambuco-Brazil), Hydrobiologia, Vol. 232, pp. 133-143.

Neumann-Leitão, S., Koening, M.L., Macêdo, S.J., Medeiros, C., Muniz, K. and Feitosa, F.N. (1999), Plankton disturbance at Suape estuarine area - Pernambuco-Brazil after a port complex implantation, in Usó, J.L. and Brebbia, C.A. (Eds.), Second International Conference on Ecosystems and Sustainable Development, Advances in Ecological Sciences, Vol. 2, pp. 47-56.

Neumann, V.H.M.L. (1991), Geomorfologia e sedimentologia quaternária da área de Suape, Pernambuco (Brasil), Dissertação de Mestrado, Programa de Pós-Graduação em Geociências, Centro de Tecnologia, Universidade Federal de Pernambuco, 95 p.

Neumann, V.H., Medeiros, C., Parente, L., Neumann-Leitão, S. and Koening, M.L. (1998), Hydrodynamism, sedimentology, geomorphology and plankton changes at Suape area (Pernambuco-Brazil) after a Port Complex Implantation, Anais Academia Brasileira de Ciências, Vol. 70, n. 2, pp. 313-323.

Noriega, C.E.D, Santiago, M.F., Façanha, P., Cunha, M.G.S.; Silva, R.A., Flores, M.J.F., Araújo Filho, M., Costa, K.M.P., Eskinazi-Leça, E. and Neumann-Leitão, S. (2013), The instantaneous transport of inorganic and organic material in a highly polluted tropical estuary, Marine and Freshwater Research, Vol. 64, pp. 562-572.

Paiva, A.C.G., Chaves, P.T.C. and Araújo, M.E. (2008), Estrutura e Organização Trófica da Ictiofauna de Águas Rasas em Um Estuário Tropical, Revista Brasileira de Zoologia, Vol. 25 , n. 4, pp. 647-661.

Paranaguá, M.N. (1985-86), Zooplankton of the Suape area (Pernambuco-Brazil), Trabalhos Oceanográficos, Vol. 19, pp. 113-124.

Savenije, H.H.G. (2012), Salinity and Tides in Alluvial Estuaries, $2^{\circ}$ ed. Revisada, 163p. Disponível em: <http://www.salinityandtides.com>. 
Shaha, D.C., Cho, Y.-K., Kwak, M.-T., Kundu, S.R. and Jung, K.D. (2011), Spatial variation of the longitudinal dispersion coefficient in an estuary, Hydrology and Earth System Sciences Discussions, Vol. 15, pp. 3679-3688.

Sobral, M., Montenegro, S., Gunkel, G., Barros, A.M.L. and Aureliano, J. (2016), Evolution of the Monitoring Water Quality System in Ipojuca River Basin, Brazil, Trivent Publishing, Engineering and Industry, Vol. Watershed and River Basin Management, pp. 94-100.

Vasconcelos Filho, A.L., Guedes, D.S. and Sobrinho, D.G. (1990), Taxonomia e ecologia da fauna ictiológica da área de Suape (Pernambuco-Brasil), Trabalhos Oceanográficos da Universidade Federal de Pernambuco, Vol. 21, pp. 305-343.

Whitfield, A.K. and Elliott, M. (2011), Ecosystem and Biotic Classifications of Estuaries and Coasts, in Wolanski, E. and McLusky, D.S. (Eds.), Treatise on Estuarine \& Coastal Science, Academic Press, Waltham, pp. 99-124. 